\title{
KAJIAN KONSEP RASIONAL DAN MASLAHAH DALAM PENGEMBANGAN PERBANKAN SYARIAH: STUDI PERBANDINGAN ANTARA INDONESIA DAN MALAYSIA
}

\author{
Dimas Bagus Wiranatakusuma', Masyhudi Muqorobin², Imamudin Yuliadi ${ }^{3}$ \\ ${ }^{1}$ Dosen Departemen Ilmu Ekonomi, Universitas Muhammadiyah Yogyakarta \\ 2Direktur International Program for Islamic Economics and Finance (IPIEF), \\ Departemen Ilmu Ekonomi, Universitas Muhammadiyah Yogyakarta, Indonesia \\ ${ }^{3}$ Ketua Program Studi Ilmu Ekonomi, Departemen Ilmu Ekonomi, \\ Universitas Muhammadiyah Yogyakarta, Indonesia \\ Email Korespondensi: dimas_kusuma@umy.ac.id
}

Naskah Diterima: Januari 2016; Disetujui: April 2016

\begin{abstract}
The main idea about preference and utility in Islamic perspective is to describe consumer behavior in accordance with the concept of maslahah. This essay tries to replicate the concept of maslahah by dividing into good deeds $(G)$ and bad deeds $(B)$ with certain limits of ability $(A)$. The Hicksian and Marshallian demand function is used to recover the problem by taking the comparison of Islamic banking objects between Indonesia and Malaysia. This paper uses several selected variables to measure the function of Masahah (M) as well as the ability (A). Empirically, the variables used to measure the function of Masahah are savings, financing, and yield rate. In addition, the Cobb-Douglas (CD) utility function is used to describe the maslahah model. The study results show that Indonesia has a bigger problem compared to Malaysia based on its Shariah banking practices. However, more business has to be done by the Sharia Bank in Indonesia to maintain the maslahah level than in Malaysia because maslahah is seen as a manifestation of good effort (Eg).

Keywords: sharia banking, maslahah, Cobb-Douglas function, Indonesia, and Malaysia.

JEL Classification: C61, D11, Z120.
\end{abstract}

Abstrak: Gagasan utama tentang preferensi dan utilitas dalam perspektif Islam adalah untuk menggambarkan perilaku konsumen sesuai dengan konsep maslahah. Tulisan ini pada dasarnya mencoba untuk mengkerangkakan konsep maslahah dengan membagi ke dalam perbuatan baik (G) dan perbuatan buruk (B) dengan batas kemampuan tertentu (A). Fungsi permintaan Hicksian dan Marshallian digunakan untuk mengkerangkakan maslahah dengan mengambil perbandingan objek perbankan Syariah antara Indonesia dan Malaysia. Tulisan ini menggunakan beberapa variabel terpilih untuk mengukur fungsi Maslahah (M) serta kemampuan (A). Secara empiris, variabel yang digunakan untuk mengukur fungsi Maslahah yaitu simpanan, pembiayaan, dan tingkat imbal hasil. Selain itu, fungsi utilitas Cobb-Douglas (CD) digunakan untuk menjelaskan model maslahah. Hasil kajian menunjukkan bahwa Indonesia memiliki maslahah lebih besar dibandingkan dengan Malaysia berdasarkan praktik perbankan Syariahnya. Namun, lebih banyak usaha yang harus dilakukan oleh Bank Syariah di Indonesia untuk mempertahankan tingkat maslahah dibandingkan di Malaysia karena maslahah dipandang sebagai manifestasi dari usaha baik (Eg).

Kata kunci: perbankan syariah, maslahah, fungsi Cobb-Douglas, Indonesia, and Malaysia.

Klasifikasi JEL: C61, D11, Z120. 


\section{PENDAHULUAN}

Menurut Kamus Oxford, rasionalitas didefinisikan sebagai segala sesuatu yang didasarkan pada atau sesuai dengan alasan atau logika, mampu berpikir bijaksana atau logis serta memiliki kapasitas untuk berargumen. Dalam konteks ekonomi, menurut Menestrel (2001), bahwa antara rasionalitas berekonomi dan perilaku etik berada pada arah yang berlawanan. Hal ini karena menurutnya berekonomi memerlukan pengorbanan, dan tidak terlalu peka terhadap etika yang ada agar tetap bisa mencapai keuntungan yang diharapkan. Berdasarkan tabel 1, perilaku yang mempertentangkan antara perilaku ekonomi dan etika, merupakan interpretasi dari perspektif ekonomi konvensional. Perspektif ini setuju bahwa perilaku konvensional akan mewujudkan tereduksinya ketegangan antara etika dan kepentingan ekonomi, yang kemudian mengakibatkan rasionalitas ekonomi. Dengan kata lain, rationalitas dibentuk setelah menghilangkan konflik antara kepentingan ekonomi dan etika, yang sebenarnya bisa diseleraskan.

Tabel 1. Reduksional Rasional Yang Tidak Rasional Dalam Sistem Konvensional

\begin{tabular}{l|l}
\hline \multicolumn{1}{c|}{ Karakteristik } & \multicolumn{1}{c}{ Pernyataan Yang Setara } \\
\hline Profit selalu etis & Perilaku yang tidak etis adalah tidak pernah membayar \\
\hline Etika adalah kebutuhan & Keuntungan selalu tidak etis \\
\hline $\begin{array}{l}\text { Perilaku yang tidak etis selalu } \\
\text { menguntungkan }\end{array}$ & Perilaku berbiaya mahal selalu etis \\
\hline Etika selalu menguntungkan & Perilaku berbiaya mahal tidak selalu etis \\
\hline
\end{tabular}

Sumber: Menestrel (2001)

Namun demikian, tidak seperti mainstream ekonomi, ekonomi Islam memposisikan rasionalitas berdasarkan sudut pandang Islam terhadap dunia (Islamic worldview) Pandangan ini pada dasarnya menempatkan paradigma tauhid (tawhidic paradigm) sebagai sumber kepercayaan dan rasionalitas. Secara detail, konsep Islam mengenai rasionalitas dibahas oleh Ahmad (1992), "tidak dapat disangkal, baik konsistensi dari kebenaran dan dalil atau kepentingan pribadi, sebagai salah satu faktor penentu utama perilaku manusia, tetapi merupakan hambatan bagi sebuah kepentingan pribadi untuk menghubungkannya dengan tanggung jawab individu dan sosial serta moralitas secara umum". Secara jelas, perbedaan rasionalitas antara dua perspektif dapat dilihat pada tabel 2.

Tabel 2. Elemen Rasionalitas Dalam Perspektif Islam dan Konvensional

\begin{tabular}{l|l|l}
\hline Unsur-Unsur Rasionalitas & \multicolumn{1}{|c}{ Konvensional } & \multicolumn{1}{c}{ Islam } \\
\hline Wordview & $\begin{array}{l}\text { Sekuler, menghilangkan setiap nilai- } \\
\text { nilai agama dan moral }\end{array}$ & $\begin{array}{l}\text { Kepercayaan pada hari } \\
\text { perhitungan }\end{array}$ \\
\hline Kepentingan pribadi & $\begin{array}{l}\text { Memaksimalkan kepentingan pribadi } \\
\text { tanpa batas }\end{array}$ & $\begin{array}{l}\text { Menyadari kepentingan pribadi } \\
\text { dan batasan terhadapnya } \\
\text { berdasarkan Syariah }\end{array}$ \\
\hline
\end{tabular}

Sumber: Ramli dan Mirza (2007)

Konsep rasionalitas dalam perspektif Islam kemudian diperluas ruang lingkupnya ke arah pencapaian konsep maslahah. Secara harfiah, kata maslahah didefinisikan oleh al-Shatibi (d.790) sebagai "semua hal yang mempromosikan upaya manusia mencari nafkah, keberlangsungan kehidupan manusia dan kelayakan akan hal yang terkait dengan aspek fisik dan kualitas 
Intelektualnya" (al-Shatibi, 1990). Pada dasarnya, konsep maslahah memiliki tujuan untuk menjaga dan meningkatkan tingkat kesejahteraan masyarakat melalui penafsiran syariah, termasuk pencapaian dari tujuan syariah itu sendiri (maqasid al-Syariah), yaitu mendidik sikap individul, menegakkan keadilan, dan meningkatkan kesejahteraan.

Dalam prakteknya saat ini, penerapan maslahah dapat ditelusuri melalui praktik perbankan syariah, yang ditunjukan oleh perkembangan dari sisi pembiayaan dan simpanan. Negara Malaysia dan Indonesia adalah negara yang sangat menarik untuk dikaji karena praktek-praktek perbankan Syariah terutama dari sisi aset tumbuh pesat selama lebih dari dua puluh tahun terakhir. Menurut laporan Bank Indonesia per Oktober 2012, akumulasi aset bank Syariah tumbuh luar biasa menjadi sekitar 178.6 triliun Rupiah atau 4,4 \% dari keseluruhan aset dalam sistem perbankan. Jumlah ini akan terus meningkat karena melihat ukuran dan potensi pasar yang masih luas dan kepadatan penduduk Muslim terbesar di dunia. Aspirasi mengenai optimisme ini secara terbuka dinyatakan dan ditegaskan kembali oleh Gubernur Bank Sentral Indonesia yang berpendapat "Perbankan syariah telah tumbuh positif pada tahun 2012 dan akan tetap terus positif di tahun 2013". Sementara itu, dalam kasus Malaysia, menurut laporan ekonomi tahun 2012/2013 oleh Departemen Keuangan, bisnis perbankan syariah dinyatakan terus berkembang di tujuh bulan pertama tahun 2012 dengan total aset meningkat 20,6\% menjadi RM 469,5 miliar, sekitar 24,2\% berdasarkan akumulasi aset. Pada tahun 2013, pemerintah Malaysia terus berkomitmen untuk meningkatkan kinerja perbankan dengan menyediakan kerangka hukum yang baru dalam operasionalisasi perbankan dan takaful Islam. Itu mungkin menyiratkan sebuah komitmen bahwa praktik perbankan Islam memerlukan pengakuan hukum mengenai persyaratan kontrak yang sesuai dengan syariah. Oleh karena itu, pengembangan perbankan syariah di kedua negara mendapatkan perhatian yang sangat besar dan kajian luar biasa analisis mengenai sudah sejauh mana praktik perbankan syariah memenuhi dan memuaskan kebutuhan umat secara keseluruhan.

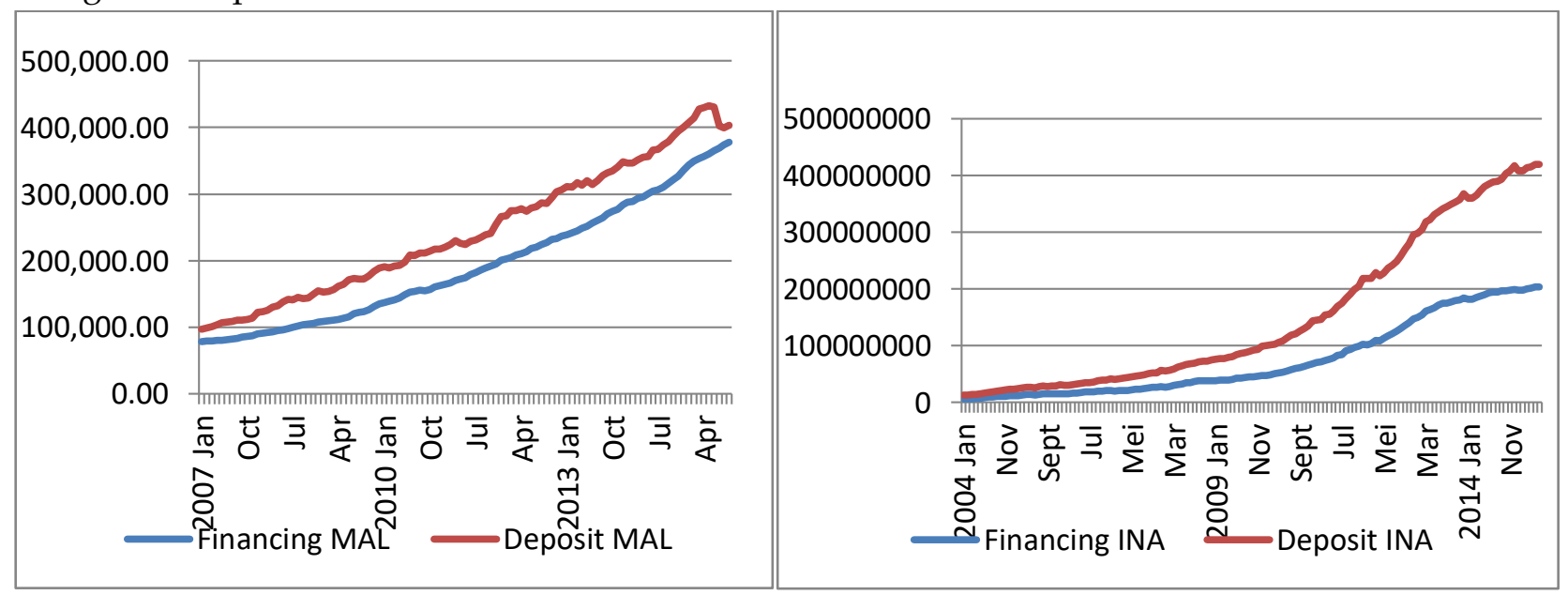

Sumber: Bank Indonesia dan Bank Negara Malaysia (2015)

Gambar 1. Perkembangan Kinerja Perbankan Syariah di Indonesia dan Malaysia 
Gambar 1 menunjukkan kinerja perbankan syariah di Indonesia dan Malaysia berdasarkan jumlah deposito dan pembiayaan hingga Juli 2015. Di Indonesia, jumlah pembiayaan yang diberikan cenderung melebar atau menjauhi dari jumlah depositonya. Berbeda sedikit di Malaysia, walaupun jumlah deposito lebih besar dari pembiayaannya, gapnya cenderung stabil. Hal ini mengindikasikan bahwa bank syariah di Indonesia menerapkan manajemen resiko yang lebih besar dan cenderung menjaga level rasio pembiayaan terhadap depositonya dalam level yang tidak terlalu besar. Namun demikian, gambar 1 di atas menyiratkan isu apakah melebarnya gap antara pembiayaan dan deposito akan memberikan level maslahah yang lebih kecil atau sebaliknya. Selain itu, kecilnya gap antara deposito dan pembiayaan di Malaysia memberikan pesan bahwa level usaha yang diberikan untuk memperbesar peran perbankan
Syariah adalah lebih besar dibanding di Malaysia, terutama dalam mendukung iklim pertumbuhan ekonomi.

Gambar 2 menunjukkan perbandingan antara suku bunga kredit dan imbal hasil (PLS) di Indonesia dan Malaysia. Ternyata, berdasarkan data runtut waktu terlihat bahwa Indonesia memiliki tingkat pengembalian suku bunga dan imbal hasil yang lebih tinggi dibanding Malaysia. Dari perspektif perbankan, besarnya tingkat pengembalian dapat mendorong mobilisasi dana kepada perbankan, namun dalam perspektif perbankan Syariah kondisi ini menunjukkan besarnya insentif untuk mendayagunakan dananya. Imbal hasil yang tinggi tentunya dapat mendorong perekonomian dan memberikan isyarat bahwa tingkat maslahah dari keberadaan bank Syariah di Indonesia dapat lebih tinggi karena besarnya insentif imbal hasil yang diberikan.

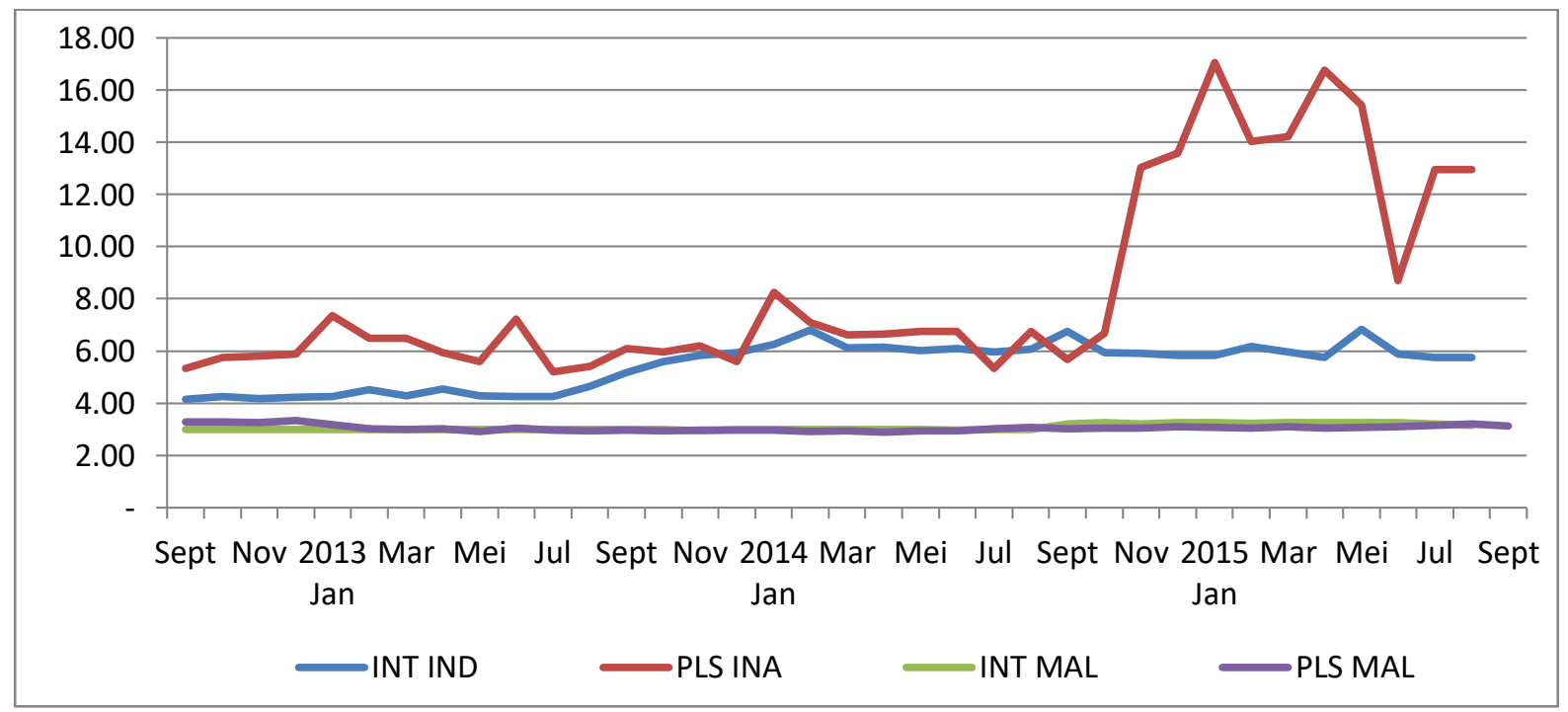

Sumber: Bank Indonesia dan Bank Negara Malaysia (2012)

Gambar 2. Komparasi Tingkat Suku Bunga dan Imbal Hasil di Perbankan Konvensional dan Syariah Indonesia dan Malaysia 
Berdasar latar belakang tersebut, tulisan ini secara empiris mencoba untuk melihat praktekpraktek saat ini Bank Syariah, terutama pada sisi deposito dan pembiayaan yang semakin meningkat dari waktu ke waktu. Secara teknis, perbankan Syariah berjalan sesuai prinsip-prinsip Syariah sehingga semua produk dan jasa yang dikeluarkan adalah sesuai Syariah. Kredibilitas akan kepatuhan Syariah karena sebagian besar Bank Syariah telah menyertakan Dewan Pengawasan Syariah. Dewan ini bertugas memberikan saran pada para bankir perbankan Syariah semua hal yang berkaitan dengan aplikasi aturan aturan hukum Islam dalam bisnis perbankan modern. Oleh karena itu, perilaku nasabah perbankan akan dikaji sepanjang penelitian dengan menerapkan konsep rasional dikombinasikan dengan maksimalisasi utilitas dalam teori konsumen.

Namun, berbeda dengan perbankan konvensional, pencapaian maslahah adalah roh utama dari penerapan sistem Islam dalam praktik perbankan Syariah. Selain itu, Indonesia dan Malaysia adalah dua tetangga yang gencar mempromosikan praktik perbankan Syariah, sehingga relevan menjadi objek pengamatan. Oleh karena itu, tujuan utama dari tulisan ini adalah untuk mengukur tingkat maslahah dan usaha oleh perbankan Syariah mengacu pada konsep utilitas berdasar ekonomi mikro modern.

\section{METODE PENELITIAN}

Tulisan ini menggunakan data runtut waktu mulai Juli 2012 hingga Juli 2015. Data diperoleh dari Bank Indonesia dan Bank Negara Malaysia. Untuk mengukur konsep rasionalitas tulisan ini menggunakan konsep utilitas dengan memanfaatkan fungsi Cobb-Douglas. Dalam model pilihan konsumen, utilitas Cobb-Douglas (CD) secara luas digunakan dapat menjelaskan secara empiris. Fungsi ini secara empiris diterapkan dengan mengukur beberapa variabel, sebagai berikut:

(a) Konsep maslahah secara jelas mengacu pada utilitas yang dihitung sebagai perbuatan baik atau buruk. Tulisan ini mencoba untuk menghubungkan konsep rasionalitas dengan aplikasi perbankan Syariah di Indonesia dan Malaysia. M(G) adalah proxy dari "pembiayaan" oleh perbankan syariah sebagai variabel yang digunakan sesuai dengan aksioma (1) di atas. Hal ini karena pembiayaan adalah penyaluran dana yang tersedia untuk proyek-proyek yang sesuai prinsip Islam yang pada akhirnya dapat meningkatkan manfaat bagi manusia secara positif. Sementara itu, variabel kredit dalam bank konvensional sebagai proxy untuk mengukur M(B) karena dana yang disalurkan oleh bank konvensional ada kalanya dipergunakan untuk aktivitas yang tidak selalu memenuhi prinsip syariah, misalnya mengalokasikan dana untuk mendorong proyek-proyek yang melanggar aturan Syariah, seperti perjudian, dan bisnis minuman keras. Singkatnya, $M(G)$ diukur dengan mengambil jumlah skema pembiayaan yang disalurkan oleh bank syariah selama periode pengamatan. Demikian pula, $\mathrm{M}(\mathrm{B})$ dihitung dengan memasukkan jumlah kredit yang disalurkan oleh bank konvensional selama periode penelitian.

(b) Kemudian, menurut aksioma (1) di atas, kita perlu proxy untuk variabel $G$ dan B. Dalam kasus perbankan, sisi deposit ini digunakan untuk mengukur perilaku rasionalitas pada masingmasing perbankan, Syariah dan konvensional. Penggunaan deposit adalah preferensi nasabah dalam menempatkan dana mereka di Bank konvensional atau Syariah sehingga dapat dimasukkan dalam analisis. Praktik Bank Syariah hanya memenuhi dan memenuhi prinsip Syariah, maka menempatkan dana di Bank Syariah dapat dianggap sebagai perbuatan baik $(G)$, sebaliknya, 
sementara dana disimpan konvensional dikelompokkan sebagai perbuatan buruk (B).

(c) Dalam aksioma di atas, konsep rasional juga memasukkan kemungkinan perbuatan baik atau buruk (п). Dalam hal ini, probabilitas yang dikenakan untuk $G$ dan B, yakni 0,5 atau memiliki proporsi yang sama, dalam arti bahwa manusia dianggap memiliki kecenderungan yang proporsional dalam berperilaku dan membuat pilihan karena rasionalitas mereka sendiri.

(d) Terakhir adalah mengenai tingkat pengembalian sebagai proxy untuk variabel usaha (E). Tingkat pengembalian dalam bentuk bunga untuk mengukur usaha buruk (Eb), sementara itu bagi hasil (PLS) konsep tersebut dilakukan untuk mengungkap usaha baik (Eg). Pada dasarnya, tingkat pengembalian adalah harga dari modal yang diinvestasikan oleh nasabah. Tapi, setelah dana tersedia di pasar, bank sebagai lembaga intermediasi bertindak sebagai pengumpul dana mendistribusikan mereka berdasarkan motif keuntungan. Oleh karena itu, harga modal komersial digunakan untuk menarik dan menyerap dana di pasar. Oleh karena itu, harga modal disebut bunga dalam konvensional dan bagi hasil dalam konsep Islam yang dimanfaatkan dan dihargai sebagai usaha (E).

\section{HASIL DAN PEMBAHASAN}

\section{Etika dan Rasionalitas dalam Ekonomi Islam}

Pada prinsipnya etika adalah perilaku bermoral yang diterima oleh kesepakatan sosial. Dalam Islam, etika yang kemudian mengarah kepada rasionalitas adalah kesepakatan sosial yang didasarkan pada konsep maslahah. Oleh karena itu, Islam memiliki standar sendiri yang segala sesuatunya tidak hanya berdasarkan pada kesepakatan sosial tetapi dibatasi oleh nilai-nilai Shariah.

\section{Penerapan Rasionalitas dalam Islam}

Dalam menjelaskan model rasionalitas, kita perlu mengembangkan variabel pengamatan dan definisinya, dan perannya dalam model yang dikembangkan, yaitu:

(a) Lemma atau aksioma 1: Maslahah adalah transformasi monotonic dari falah

- Perbuatan Baik (G) adalah setiap kebajikan dari perilaku manusia

- Perbuatan Buruk (B) merupakan kegiatan yang tidak sesuai dengan prinsip Syariah Islam

- M (G) adalah maslahah yang mungkin diperoleh jika seseorang melakukan perbuatan baik (G)

- $\mathrm{M}$ (B) adalah mafsadat yang diperoleh setelah seseorang jika melakukan perbuatan melanggar hukum (B)

- Baik M (G) atau M(B) memiliki proporsi ditentukan meskipun tidak dapat dihitung, tapi kami berharap $\mathrm{M}(\mathrm{G})>\mathrm{M}(\mathrm{B})$

- Setiap perbuatan baik (G) akan diberikan keberkahan Allah, sebaliknya untuk perbuatan buruk (B).

(b) Lemma atau aksioma 2: setiap perbuatan baik akan meningkatkan probabilitas (ng) untuk mendapatkan $\mathrm{M}(\mathrm{G})$ di akhirat. Sebaliknya, setiap perbuatan buruk (B) akan memiliki probabilitas (п) untuk mendapatkan $\mathrm{M}(\mathrm{B})$

- Setiap orang diberikan kemampuan (A) oleh Allah SWT akan bertemu untuk melakukan perbuatan tertentu.

- Setiap orang mempunyai keinginan untuk melakukan perbuatan baik $(\mathrm{G})$ dan perbuatan buruk (B). Kedua perbuatan tersebut diperlukan usaha (E). Dalam konteks ini, misalnya $\mathrm{Eg}$ adalah upaya yang diarahkan untuk mencapai kebaikan, dan Eb diarahkan ke kejahatan.

(c) Lemma atau aksioma 3: Hasil yang besar memerlukan usaha besar, demikian sebaliknya. 
$\mathrm{G}=\mathrm{f}(\mathrm{Eg})$ dan $\mathrm{B}=\mathrm{f}(\mathrm{Eb}), \boldsymbol{\Delta} \mathrm{B} / \boldsymbol{\Delta} \mathrm{Eb}>0$, dan $\boldsymbol{\Delta} \mathrm{G} /$ $\Delta \mathrm{Eg}>0$.

Setiap upaya yang dilakukan oleh agen ekonomi akan dibatasi oleh suatu tingkat kemampuan tertentu atas dirinya.

(d) Lemma atau Aksiom 4: Usaha dan intensitas yang sama akan sesuatu akan memberikan hasil yang proporsional, baik diarahkan untuk perbuatan baik (G) atau perbuatan buruk (B), $\Delta$ B / $\Delta \mathrm{Eb}=\Delta \mathrm{G} / \boldsymbol{\Delta E g}$, Misalnya atau $n g=n b$

(e) Lemma atau aksioma 5: Karena kehadiran maslahah adalah yang dikejar, sehingga konsep maslahah sudah tidak lagi mengikuti konsep marjinal yang semakin berkurang. Hal ini menyiratkan bahwa: $\Delta \Pi g / \Delta \mathrm{G}>\Delta \Pi b / \Delta \mathrm{B}>0$.

Berdasarkan aksioma di atas, kita dapat simpulkan bahwa (1) maslahah untuk perbuatan baik akan meningkat ketika setiap individu memperbesar kemungkinan untuk melakukan perbuatan baik dan usaha menuju kebaikan secara maksimal, (2) sementara itu, mafsadat untuk perbuatan buruk meningkat ketika individu berkomitmen untuk meningkatkan probabilitas menuju keburukan disertai usaha untuk melakukannya.

\section{Maslahah Teori dalam Hukum Islam}

Secara harfiah, kata maslahah berasal dari kata kerja " saluha " , yang menunjukkan baik, tepat, jujur atau hanya seseorang atau sesuatu. Antonim nya, mafsadah menunjukkan sesuatu yang berbahaya dan merusak. Penggunaan maslahah sebagai sumber hukum independen telah dianjurkan oleh banyak ahli hukum kontemporer dan reformis Muhammad Abduh (d.1905), Rashid Rida (d.1935), Ibn ' Ashur (d.1973) dan Muhammad Sa'id Ramadhan al-Buti. Mendukung prinsip didasarkan pada gagasan bahwa hukum Islam diturunkan untuk melayani, inter alia, kesejahteraan manusia (Lubis, 1995, ms. 10). Oleh karena itu, Semua hal yang melestarikan sumur-yang ada di masyarakat di baris dengan tujuan dari syariat dan oleh karena itu harus mengejar dan secara hukum diakui. Namun, ada pendapat di kalangan para Dewan juri klasik dalam menerapkan prinsip maslahah sebagai faktor yang menentukan dalam hukum Islam. Karena ambiguitas dalam mendefinisikan batas (sejauh pembenaran kesejahteraan manusia bisa digunakan untuk menentukan hukum), para Dewan juri klasik telah berbeda dalam mengakui keabsahan maslahah sebagai sumber hukum. Beberapa sarjana mengklaim bahwa al-Syafi'i tidak menggunakan maslahah sebagai bukti hukum independen (dalil) karena ia benar-benar terbatas penggunaan pendapat pribadi (ra'y) untuk qiyas (analogi). Menurut al-Syafi'i, menerapkan konsep maslahah akan melebihi keterbatasan diizinkan penggunaan penalaran hukum manusia dalam menyusun baru hukum (Lubis, 1995). Mungkin, al-Syafi'i berusaha untuk menggambarkan metodologi hukum (Al-Qur'an, sunnah, qiyas dan ijmak ') dijelaskan dalam alRisalah sebagai sumber mandiri hukum yang dapat menjawab semua pertanyaan dalam kehidupan seorang Muslim. Al-Syafi'i percaya bahwa sumber-sumber hukum cukup untuk menutupi maslahah manusia. Dia pikir Syari'at membawa kesadaran penuh yang semua maslahah dan tidak ada maslahah di luar kerangka yang pada umumnya.

Diskusi tentang deposito dalam bank Syariah terbagi menjadi tiga kelompok. Pertama, adalah studi yang terutama difokuskan pada tingkat pengembalian tingkat deposito dan faktor-faktor yang mempengaruhi volatilitasnya. Chong dan Liu (2008) menyelidiki hubungan antara pengembalian deposito bank Syariah dengan bunga deposito tetap konvensional di Malaysia. Menggunakan data runtut waktu berkisar antara April 1995- April 2004, Chong dan Liu (2008) mampu memberikan bukti bahwa tingkat pengembalian deposito di bank Syariah 
bergantung pada suku bunga deposito bank umum konvensional.

Kedua, beberapa studi juga membahas jumlah deposito bank dan faktor-faktor penentunya. Haron dan Azmi (2008) menggunakan variabel ekonomi makro sebagai penjelasan variabel untuk memprediksi perilaku deposito di Malaysia dan mengungkapkan bahwa pertumbuhan ekonomi dan peningkatan pasokan uang, indeks komposit dan indeks harga konsumen, meningkatkan deposito bank syariah. Selain itu, Haron dan Azmi (2008) juga secara empiris membuktikan bahwa setiap peningkatan tingkat suku bunga, jumlah deposito bank umum konvensional akan meningkat dan deposito bank Syariah akan menurun, dan sebaliknya. Hasil yang sama ditemukan oleh Rohmah (2006) dengan kasus Indonesia terjadi kointegrasi jangka panjang antara deposito bank Syariah dengan tingkat pengembalian deposito konvensional, tingkat pendapatan dan jumlah cabang Bank Syariah. Haron dan Ahmad (2000), juga menyelidiki bahwa efek suku bunga konvensional dan tingkat keuntungan pada dana yang disimpan dengan sistem perbankan syariah di Malaysia. Hubungan negatif muncul antara suku bunga bank umum konvensional dan total deposito di Bank Syariah sehingga memberikan bukti nasabah di perbankan Syariah menggunakan ukuran tingkat pengembalian hasil deposito dalam memaksimalkan tingkat utilitasnya.

Sementara itu, Kasri dan Kasim (2009) memberikan kesimpulan penelitian yang Mendukung Haron dan Ahmad (2000), Rohmah (2006), Haron dan Azmi (2008) dan Kasim et al (2009), bahwa deposit bank Syariah berkorelasi secara berlawanan dengan tingkat suku bunga. Abduh et al. (2011) meneliti hubungan antara variabel makro ekonomi dan krisis keuangan terhadap fluktuasi total deposito di Malaysia pada industri perbankan syariah. Dengan menggunakan teknik model koreksi kesalahan (VECM), Abduh et al. (2011) menemukan inflasi memiliki efek negatif terhadap total deposito. Sedangkan variabel-variabel makro ekonomi lainnya tidak terbukti berdampak pada total deposito. Menariknya, krisis keuangan secara signifikan dan positif mempengaruhi total deposito perbankan syariah di Malaysia. Ketiga, adalah kelompok studi yang menggabungkan antara tingkat pengembalian deposito bank dan volume deposito. Bacha's (2004) membahas kausalitas hubungan antara suku bunga bank umum konvensional dengan tingkat pengembalian perbankan syariah serta antara konvensional tetap-deposito dan deposito bank syariah. Dengan menggunakan data runtut waktu dari Januari 1994 hingga Juli 2003, studi menunjukkan bahwa perubahan suku bunga bank konvensional dan total deposito menyebabkan perubahan dalam tingkat pengembalian dan total deposito bank syariah.

Zainol dan Kasim (2010) meneliti faktor penentu tingkat pengembalian dan total deposito di perbankan Syariah. Dengan data bulanan selama 10 tahun dari Januari 1997 sampai Oktober 2008, mereka menemukan bahwa tingkat pengembalian Bank Syariah dan suku bunga bank konvensional mengalami kointegrasi dan memiliki keseimbangan jangka panjang. Selain itu, studi juga menunjukkan adanya motif profit pada nasabah bank syariah karena korelasi yang negatif dan signifikan antara bunga deposito mudharabah dengan total deposit. Dengan kata lain, nasabah perbankan syariah masih berdasar pada profit motif daripada regilius motif dalam melakukan transaksi di perbankan syariah, dan hal ini oleh para nasabah dipandang perilaku yang rasional. 


\section{Membangun Fungsi Lagrange}

(a) Berdasar Fungsi Permintaan Marshalian

Singkatnya, pada pendekatan ini, maslahah akan maksimal namun tergantung pada kemampuan, diwakili oleh variabel usaha (E).

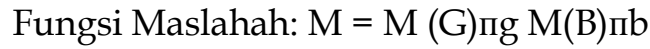

Fungsi Kemampuan: A = Eg.G + Eb.B

Fungsi Lagrange:

$\mathrm{L}=\mathrm{M}(\mathrm{G}) \Pi g \mathrm{M}(\mathrm{B}) \Pi b+\delta$ (A-Eg. G-Eb. B), nilai probabilitas (п), sama sebesar 0.5

$\mathrm{L}=\mathrm{M}(\mathrm{G}) 0.5 \mathrm{M}(\mathrm{B}) 0.5+\delta$ (A-Eg. G-Eb. B)

Hasil dari the first-order conditions:

$\Delta \mathrm{L} / \Delta \mathrm{G}=0.5 . \mathrm{M}(\mathrm{G})-0.5 \mathrm{M}(\mathrm{B}) 0.5-\delta \mathrm{Eg}=0$.

$\Delta \mathrm{L} / \Delta \mathrm{B}=0.5 . \mathrm{M}(\mathrm{G}) 0.5 \mathrm{M}(\mathrm{B})-0.5-\delta \mathrm{Eb}=0$

$\Delta \mathrm{L} / \Delta \delta=\mathrm{A}-\mathrm{Eg} . \mathrm{G}-\mathrm{Eb} . \mathrm{B}=0$

Persamaan (1) dan (2) disederhanakan menjadi:

$(\Delta \mathrm{L} / \Delta \mathrm{G}) /(\boldsymbol{\Delta L} / \Delta \mathrm{B})=(0.5 \cdot \mathrm{M}(\mathrm{G})-0.5 \mathrm{M}(\mathrm{B}) 0.5-\delta \mathrm{Eg}) /(0.5 . \mathrm{M}(\mathrm{G}) 0.5 \mathrm{M}(\mathrm{B})-0.5-\delta \mathrm{Eb})$

$\delta \mathrm{Eg} / \delta \mathrm{Eb}=(0.5 . \mathrm{M}(\mathrm{G})-0.5 \mathrm{M}(\mathrm{B}) 0.5) /(0.5 . \mathrm{M}(\mathrm{G}) 0.5 \mathrm{M}(\mathrm{B})-0.5)$

$\mathrm{Eg} / \mathrm{Eb}=\mathrm{M}(\mathrm{B}) / \mathrm{M}(\mathrm{G})$

$\mathrm{Eb} .=\mathrm{Eg}(\mathrm{M}(\mathrm{G}) / \mathrm{M}(\mathrm{B}))$ or $\mathrm{Eg}=\mathrm{Eb} .(\mathrm{M}(\mathrm{B}) / \mathrm{M}(\mathrm{G}))$

Kemudian, subtitusikan persamaan (3) ke (4) menjadi:

$\mathrm{A}=\mathrm{Eg} \cdot \mathrm{G}+\mathrm{Eb} \cdot \mathrm{B}$

$A=E g \cdot G+\operatorname{Eg}(M(G) / M(B)) \cdot B$

Eg. $G=A-(E g .(M(G) / M(B)) \cdot B)$

$\mathrm{G}=(\mathrm{A}-(\mathrm{Eg} \cdot(\mathrm{M}(\mathrm{G}) / \mathrm{M}(\mathrm{B})) . \mathrm{B})) / \mathrm{Eg}$ or $\mathrm{B}=(\mathrm{A}-\mathrm{Eb} \cdot(\mathrm{M}(\mathrm{B}) / \mathrm{M}(\mathrm{G})) \cdot \mathrm{G})) / \mathrm{Eb}$

Berdasar pada persamaan (5), persamaan utilitas dapat diperoleh dengan:

$\mathrm{M}=(\mathrm{M}(\mathrm{G}), \mathrm{M}(\mathrm{B}), \mathrm{A})=\mathrm{M}(\mathrm{G}, \mathrm{B})=((\mathrm{A}-\mathrm{Eg} .(\mathrm{M}(\mathrm{G}) / \mathrm{M}(\mathrm{B})) . \mathrm{B}) / \mathrm{Eg}) 0.5 \cdot((\mathrm{A}-\mathrm{Eb} \cdot(\mathrm{M}(\mathrm{B}) / \mathrm{M}(\mathrm{G})) \cdot \mathrm{G} / \mathrm{Eb})) 0.5$

$\mathrm{M}=((\mathrm{A}-\mathrm{Eg} .(\mathrm{Eb} / \mathrm{Eg}) . \mathrm{B}) / \mathrm{Eg})) 0.5$ ((A-Eb. (Eg/Eb). G)/Eb)) 0.5

$\mathrm{M}=((\mathrm{A}-\mathrm{Eb} \cdot \mathrm{b}) / \mathrm{Eg})) 0.5$. ((A-Eg.G)/Eb) $) 0.5$

$\mathrm{M}=((\mathrm{A}-(\mathrm{A}-\mathrm{Eg} \cdot \mathrm{G}) / \mathrm{G})) 0.5 \cdot((\mathrm{A}-(\mathrm{A}-\mathrm{Eb} \cdot \mathrm{B}) / \mathrm{Eb})) 0.5$

$\mathrm{M}=(\mathrm{Eg} . \mathrm{Eb}) 0.5$

(b) Berdasar Fungsi Permintaan Hicksian

Secara singkat, Hicksian mengasumsikan bahwa maksimalisasi dari maslahah telah di titik skala optimal. Sehingga, yang perlu dijabarkan adalah level usaha (E) yang kemudian membawa untuk memaksimalkan maslahah selalu pada titik optimal. Fungsi Lagrange digunakan untuk menghitung posisi tersebut dengan langkah-langkah sebagai berikut:

Fungsi Maslahah: A = Eg.G + Eb.B

Fungsi Kemampuan: $M=M(G) 0.5 . M(B) 0.5$

Fungsi Lagrange Function: $\mathrm{L}=\mathrm{Eg} . \mathrm{G}+\mathrm{Eb} . \mathrm{B}+\delta(\mathrm{M}-\mathrm{M}(\mathrm{G}) 0.5 \cdot \mathrm{M}(\mathrm{B}) 0.5)$

Hasil dari first order conditions:

$\Delta \mathrm{L} / \Delta \mathrm{G}=\mathrm{Eg}-0.5 \delta \mathrm{M}(\mathrm{G})-0.5 \mathrm{M}(\mathrm{B}) 0.5=0$

$\Delta \mathrm{L} / \Delta \mathrm{B}=\mathrm{Eb}-0.5 \delta \mathrm{M}(\mathrm{G}) 0.5 \mathrm{M}(\mathrm{B})-0.5=0$

$\Delta \mathrm{L} / \Delta \delta=\mathrm{M}-\mathrm{M}(\mathrm{G}) 0.5 \mathrm{M}(\mathrm{B}) 0.5=0$

Subtitusi persamaan (1) dan (2),

$\mathrm{Eg} / \mathrm{Eb}=\mathrm{M}(\mathrm{B}) / \mathrm{M}(\mathrm{G})$, where $\mathrm{M}(\mathrm{B})=(\mathrm{Eg} / \mathrm{Eb}) \cdot \mathrm{M}(\mathrm{G})$, and $\mathrm{M}(\mathrm{G})=\mathrm{M}(\mathrm{B}) .(\mathrm{Eb} / \mathrm{Eg})$.

Kemudian subtitusikan persamaan (4) ke (3), 
$\mathrm{M}=\mathrm{M}(\mathrm{G}) 0.5 .((\mathrm{Eg} / \mathrm{Eb}) \cdot \mathrm{M}(\mathrm{G})) 0.5$

$\mathrm{M}=\mathrm{M}(\mathrm{G})(\mathrm{Eg} / \mathrm{Eb}) 0.5, \mathrm{~Eb}=(\mathrm{M}(\mathrm{G}) / \mathrm{M}) 2 . \mathrm{Eg}$.

Subtitusikan persamaan (11) ke persamaan $\mathrm{M}=\mathrm{M}(\mathrm{B}) 0.5((\mathrm{M}(\mathrm{B}) . \mathrm{Eb} / \mathrm{Eg})) 0.5$

$\mathrm{M}=\mathrm{M}(\mathrm{B})(\mathrm{Eb} / \mathrm{Eg}) 0.5, \mathrm{Eg}=(\mathrm{M}(\mathrm{B}) / \mathrm{M}) 2 \mathrm{~Eb}$.

Subtitusikan persamaan (11) dan (12) ke dalam persamaan A = Eg.G +Eb.B

$\mathrm{A}=(\mathrm{M}(\mathrm{B}) / \mathrm{M}) 2 . \mathrm{Eb}+(\mathrm{M}(\mathrm{G}) / \mathrm{M}) 2 . \mathrm{Eg}$

$\mathrm{A}=(\mathrm{M}(\mathrm{B}) 2 . \mathrm{Eb}+\mathrm{M}(\mathrm{G}) 2 . \mathrm{Eg}) / \mathrm{M} 2$

$A=(M(G) \cdot E g \cdot M(B)+M(B) \cdot E b \cdot M(G)) / M 2$

$\mathrm{A}=(\mathrm{M}(\mathrm{G}) \mathrm{M}(\mathrm{B})(\mathrm{Eg}+\mathrm{Eb})) / \mathrm{M} 2$

$\mathrm{A}=(\mathrm{M} 2(\mathrm{Eg}+\mathrm{Eb})) / \mathrm{M} 2$

$\mathrm{A}=\mathrm{Eg}+\mathrm{Eb}$.

Persamaan Lagrange di atas memberikan beberapa hal yang menarik, diantaranya:

a) Persamaan (4) dan (12) menunjukkan usaha yang diarahkan untuk perbuatan buruk (B) akan menurunkan maslahah (MG) dan peningkatan mafsadat (MB). Oleh karena itu, segala usaha harus diarahkan kepada upaya yang baik (Eg) yang akan meminimalkan kerugian dalam masyarakat.

b) Persamaan (5) menyiratkan bahwa perbuatan baik $(G)$ dapat dicapai setelah kemampuan (A), yakni usaha (E) diarahkan untuk perbuatan baik (Eg) adalah lebih besar daripada usaha (E) untuk melakukan perbuatan buruk (B), sehingga, pada akhirnya hal itu dapat meminimalkan mafsadat (MB)

c) Berdasarkan persamaan (6), maksimalisasi maslahah dengan fungsi permintaan Marshalian, tergantung pada pengejaran usaha (E), baik yang berbentuk usaha baik $(\mathrm{Eg})$ ataupun buruk $(\mathrm{Eb})$. Oleh karena itu, maslahah akan dominan jika upaya diarahkan perbuatan baik (Eg) diupayakan oleh manusia, khususnya Muslim. Sementara itu, persamaan (13), berdasar fungsi permintaan Hicksian, maslahah akan tetap maksimal tergantung pada tingkat upaya yang dilakukan (E), apakah dominan oleh usaha baik (Eg) atau usaha buruk $(\mathrm{Eb})$.

\section{Penerapan Konsep Rasionalitas pada Praktik Perbankan}

Grafik 3 menunjukkan hasil empiris dari pendekatan fungsi permintaan Marshalian (MDF) dan Hicksian (HDF) dengan studi kasus perbankan Syariah di Indonesia dan Malaysia. Hasilnya menunjukkan bahwa (1) dari segi tingkat maslahah, perbankan Syariah di Indonesia lebih tinggi daripada di Malaysia, (2) usaha yang lebih tinggi diperlukan dan sebaiknya dilakukan oleh perbankan Syariah di Indonesia agar tetap dapat memaksimalkan maslahah dibandingkan perbankan Syariah di Malaysia. Temuan-temuan di atas dapat diuraikan lebih lanjut dengan mempertimbangkan kegiatan perbankan Syariah di kedua negara masing-masing, sebagai berikut:

a) Dengan mengacu pada definisi maslahah yang merupakan segala perhatian yang diarahkan untuk meningkatkan kualitas kehidupan manusia baik secara fisik dan intelektual. Pencapaian maslahah itu diharapkan salah satunya bisa melalui praktik perbankan Syariah dengan berbagai produk dan mekanisme transaksinya. Dengan demikian, cukup relevan untuk membenarkan bahwa tingkat maslahah di Indonesia lebih besar dibanding Malaysia karena komitmen dalam penerapan kontrak kemitraan. Menurut laporan Bank Indonesia per Oktober 2012, proporsi kontrak pembiayaan musharaka dan mudharaba sekitar $27,64 \%$ dari total pembiayaan. Sementara itu, dengan mengambil kontrak sama diterapkan oleh Bank Syariah di Malaysia, hanya sekitar 5\% dengan akad mudharaba dan musyaraka per September 2012 
yang dirilis oleh Bank Negara Malaysia. Tentu saja, kita tidak bisa hanya mengandalkan pada alasan ini untuk membenarkan penyebab rendahnya tingkat maslahah di Malaysia. Namun setidaknya, kegiatan perbankan syariah di Indonesia yang lebih banyak mengarah pada kontrak kerjasama dapat meningkatkan tingkat maslahah.

b) Selain itu, Indonesia harus lebih gencar dalam upaya membumikan praktik perbankan Syariah demi menjaga pencapaian maslahah yang optimal. Mengingat, proporssi asset perbankan Syariah masih kurang dari 5\% dibandingkan dengan konvensional aset, disamping juga keterbatasan SDM di bidang perbankan syariah. Kelemahan ini pada akhirnya menuntut tambahan usaha agar optimum maslahah dapat dipertahankan. Dengan demikian, walaupun tingkat maslahah di Indonesia lebih tinggi, akan tetapi perkembangan perbankan Syariah perlu usaha bersama yang lebih massif antara regulator, praktisi dan akademisi untuk bekerja sama secara lengkap dan komprehensif.

Grafik 3 menunjukkan tingkat Maslahah dan usaha kedua negara dalam hal Maslahah dengan menggunakan fungsi permintaan Mashallian dan Hicksian. Indonesia memiliki tingkat maslahah yang lebih tinggi dibanding Malaysia berdasar pendekatan Mashallian. Berdasarkan fungsi permintaan Hicksian menunjukkan bahwa Malaysia memiliki tingkat usaha yang besar selama periode pengamatan. Hal ini berarti tingkat maslahah yang tinggi di Indonesia perlu disertai dengan usaha yang lebih masif dengan dukungan pemerintah secara intensif. Sedangkan di Malaysia, walaupun dukungan pemerintah cukup besar, artinya upaya pemerintah lebih baik dibanding di Indonesia namun belum mampu memperluas dan memperbesar tingkat maslahah dari praktik perbankan Syariahnya.

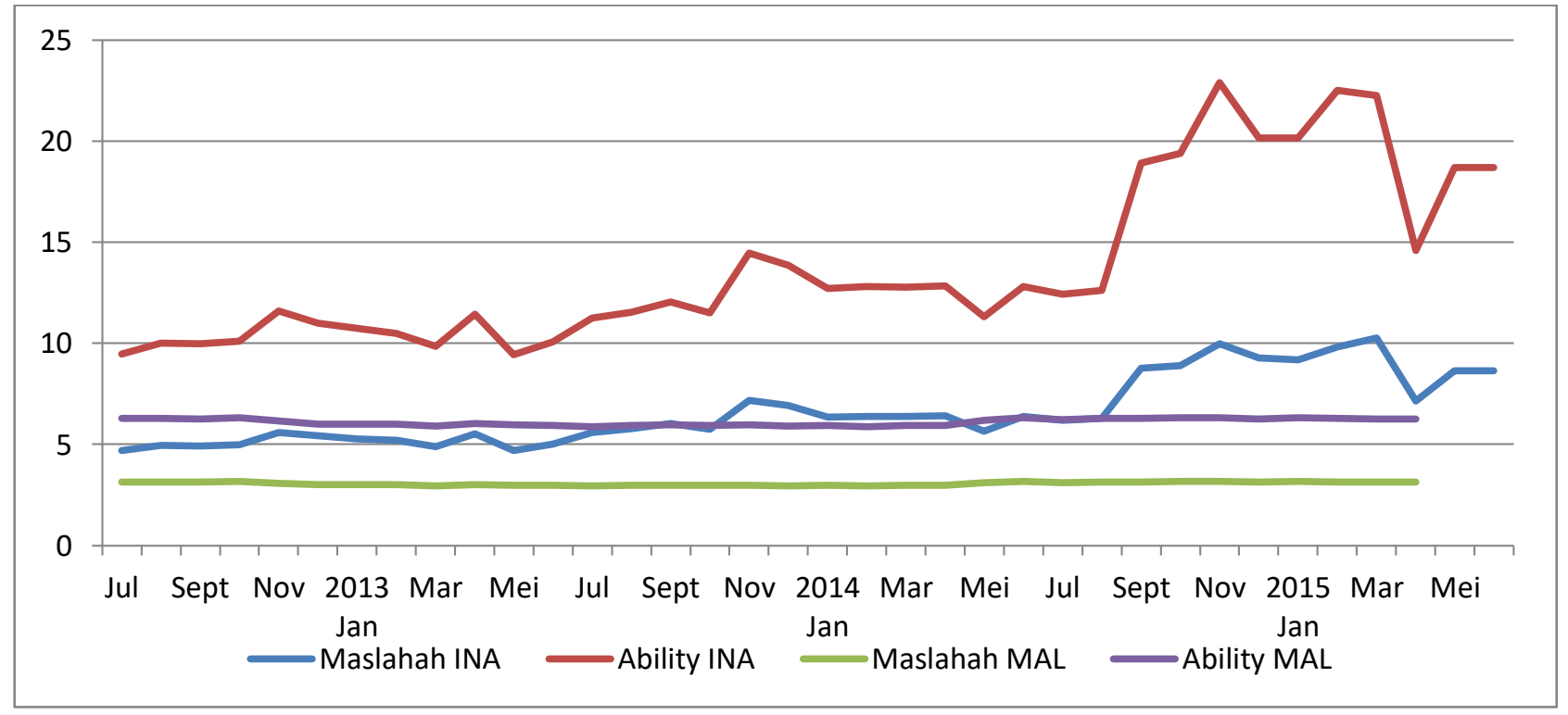

Sumber: Perhitungan Penulis

Gambar 3. Tingkat Maslahah Dan Abilitas Usaha Perbankan Syariah di Indonesia (Ina) dan Malaysia (Mal) 


\section{SIMPULAN}

\section{Simpulan}

Secara empiris mencoba untuk menerapkan konsep rasionalitas berdasar perspektif Islam dengan bertumpu pada konsep maslahah. Dengan menggunakan fungsi cobb-douglas (CD) dan mengambil praktik perbankan Islam sebagai studi kasus, hasilnya menunjukkan bahwa tingkat maslahah bisa terus-menerus ditingkatkan jika usaha diarahkan pada perbuatan baik (Eg) dimaksimalkan. Selain itu, maslahah akan termaksimalkan bila elemen usaha baik (Eg) dominan pada setiap kegiatan. Dengan mengambil Islamic banking untuk mengaplikasikan konsep rasionalitas, tulisan ini menemukan bahwa perbankan syariah di Indonesia memiliki tingkat Maslahah yang lebih tinggi dibandingkan dengan bank syariah di Malaysia. Tetapi, usaha yang terus-menerus harus dilakukan oleh Bank Syariah di Indonesia agar dapat mempertahankan tingkat maksimum Maslahah melalui praktik bank Syariah.

\section{DAFTAR PUSTAKA}

Abduh, M., Omar, M.A., and Duasa, J. (2011). The impact of crisis and macroeconomic variables towards Islamic banking deposits. American Journal of Applied Sciences, Vol. 8 No.12: 1413-1418.

Bacha, O.L. (2004). Dual banking system and interest rate risk for Islamic banks. MPRA No. 12763.

Chong, B. S. and Liu, M. H. (2008). Islamic banking: Interest-free or interest-based? Pacific-Basin Finance Journal, Vol. 17 No. 1: 125-144.

Haneef, M. A. and Hafas Furqani (2009). Developing the ethical foundation of Islamic economics: benefiting from Toshihiko Izutsu. Intelectual Discourse, Vol 17 No.2: 173-199.
Haron, S. and Ahmad, N. (2000). The effects of conventional interest rates and rate of profits on funds deposited with Islamic banking system in Malaysia. International Journal of Islamic Financial Services, Vol. 1 No. 4: 1-7.

Haron, S. and Wan Azmi, W.S. (2008). Determinants of Islamic and conventional deposits in the Malaysian banking system. Managerial Finance, Vol. 34 No. 9: 618-643.

Kasim, S. et al. (2009). Impact of monetary policy shocks on the conventional and Islamic banks in a dual banking system: evidence from Malaysia. Journal of Economic Cooperation and Development, Vol. 30 No. 1: 41-58.

Kasri, R.A. and Kasim, S. (2009). Empirical determinants of saving in the Islamic banks: Evidence from Indonesia, JKAU: Islamic Econ. Vol. 22 No. 2: 181- 201.

Ramli, A. M. et al. (2007). The Theory of Consumer Bahavior: Conventional vs Islamic. Proceedings of the 2nd Islamic Conference (iECONS2007) organized by Faculty of Economics and Muamalat, Islamic Science University of Malaysia.

Rohmah, N. (2006). Deposits determinants of Islamic bank in Indonesia: An ARDL modeling approach, Unpublished Master Thesis, Kulliyah of Economics and Management Sciences of IIUM.

Zainol, Z. and Kasim, S. (2010). An analysis of Islamic banks' exposure to rate of return risk. Journal of Economic Cooperation and Development, Vol. 31 No. 1: 59-84. 